\title{
Gunnison Sage-Grouse Lek Site Suitability Modeling
}

Open-File Report 2014-1010

U.S. Department of the Interior U.S. Geological Survey 
Front cover: Male Gunnison Sage-Grouse in full strut. Photograph by Karen Tucker, Bureau of Land Management, Uncompahgre Field Office, Montrose, Colorado.

Back cover:

Top: Male Gunnison Sage-Grouse dancing on the Lek. Photograph by Douglas Ouren, U.S. Geological Survey, Fort Collins Science Center, Fort Collins, Colorado.

Bottom: Male and Female Gunnison Sage-Grouse on the Lek. Photograph by Karen Tucker, Bureau of Land Management, Uncompahgre Field Office, Montrose, Colorado. 


\section{‡USGS \\ science for a changing world}

Prepared in cooperation with the National Audubon Society, the Bureau of Land Management, the National Park Service, the U.S. Department of Agriculture Forest Service, Colorado Parks and Wildlife, and the Habitat Partnership Program

\section{Gunnison Sage-Grouse Lek Site Suitability Modeling}

By Douglas S. Ouren, Drew A. Ignizio, Melissa Siders, Theresa Childers, Karen Tucker, and Nathan Seward

Open-File Report 2014-1010 


\section{U.S. Department of the Interior \\ SALLY JEWELL, Secretary}

\section{U.S. Geological Survey \\ Suzette M. Kimball, Acting Director}

U.S. Geological Survey, Reston, Virginia: 2014

For more information on the USGS-the Federal source for science about the Earth,

its natural and living resources, natural hazards, and the environment-visit

http://www.usgs.gov or call 1-888-ASK-USGS

For an overview of USGS information products, including maps, imagery, and publications, visit $h$ ttp://www.usgs.gov/pubprod

To order this and other USGS information products, visit $h$ ttp://store.usgs.gov

Any use of trade, firm, or product names is for descriptive purposes only and does not imply endorsement by the U.S. Government.

Although this information product, for the most part, is in the public domain, it also may contain copyrighted materials as noted in the text. Permission to reproduce copyrighted items must be secured from the copyright owner.

Suggested citation:

Ouren, D.S., Ignizio, D.A., Siders, Melissa, Childers, Theresa, Tucker, Karen, and Seward, Nathan, 2014, Gunnison sage-grouse lek site suitability modeling: U.S. Geological Survey Open-File Report 2014-1010, 18 p., http://dx.doi.org/10.3133/ofr20141010.

ISSN 2331-1258 (online) 


\section{Contents}

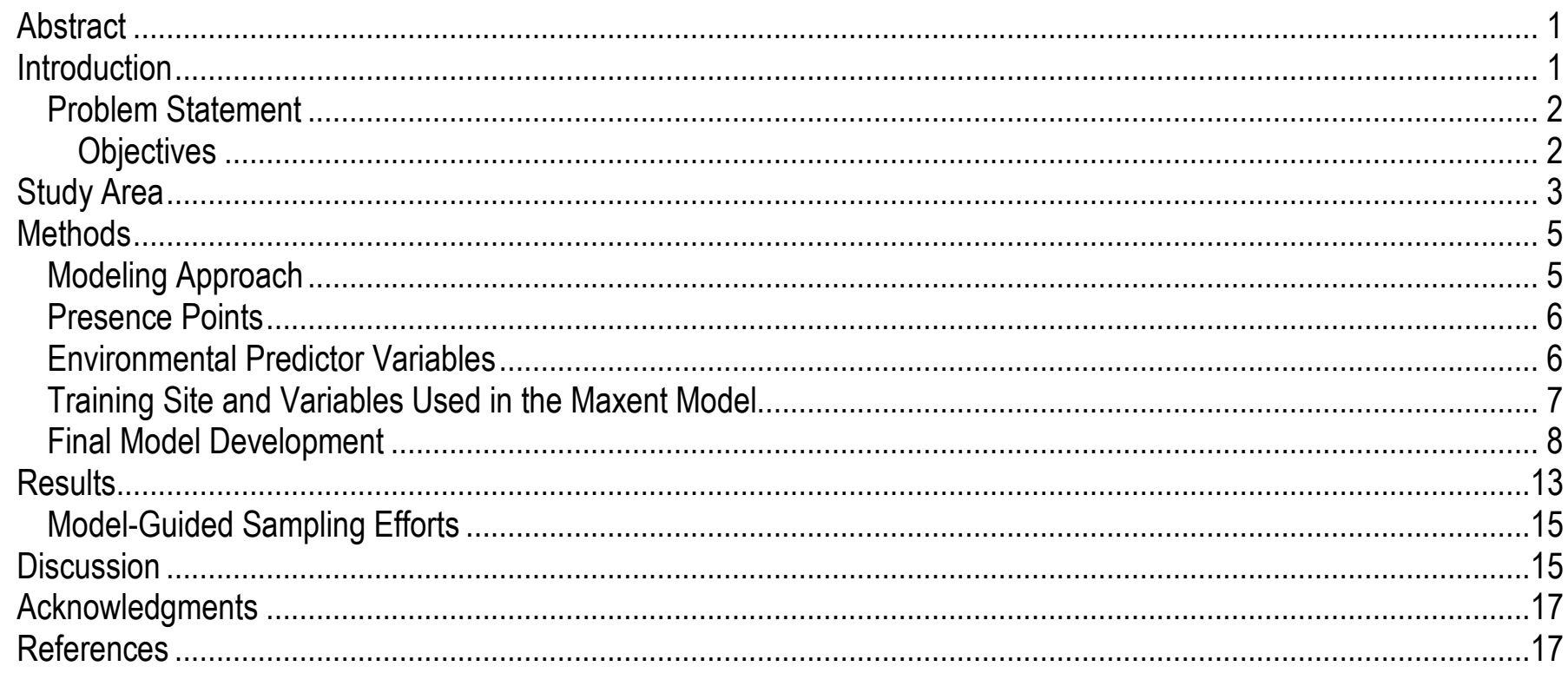




\section{Figures}

Figure 1. The Crawford study area, including jurisdictional boundaries ........................................................... 4

Figure 2. Vegetation types in the Crawford study area considered potentially suitable for sage-grouse lekking activity

Figure 3. The range of elevation values in the Crawford study area and which were considered potentially suitable $(2,310-2,420 \mathrm{~m})$ for lekking activity

Figure 4. The range of slope values in the Crawford study area and which regions were considered potentially suitable (8 degrees or less) for lekking activity

Figure 5. Areas considered potentially suitable for lekking activity (white areas) in the Crawford study area, based on slope, elevation, and vegetation type present at known leks

\section{Tables}

Table 1. Environmental predictor variables used in final Maxent model of lek suitability for Gunnison sage-grouse

Table 2. Environmental predictor variables and the range of values considered acceptable for each variable in the final model.

Table 3. Maxent output values, by class, associated rank assignments, and rank interpretations.

Table 4. Suitability of the Crawford study area (percent) for lekking activity as modeled by Maxent, by jurisdiction, before application of the binary filter ....

Table 5. Suitability of the Crawford study area (percent) for lekking activity, as modeled by Maxent, by jurisdiction, after applying the binary filter

Table 6. Relative contribution of environmental predictor variables used in the Maxent model for lek site suitability

\section{Conversion Factors}

SI to Inch/Pound

\begin{tabular}{lcl}
\hline \multicolumn{1}{c}{ Multiply } & \multicolumn{1}{c}{ By } & To obtain \\
\hline & Length & \\
\hline kilometer $(\mathrm{km})$ & 0.6214 & mile $(\mathrm{mi})$ \\
meter $(\mathrm{m})$ & 1.094 & yard $(\mathrm{yd})$ \\
\hline & Area & \\
\hline square kilometer $\left(\mathrm{km}^{2}\right)$ & 247.1 & acre \\
square kilometer $\left(\mathrm{km}^{2}\right)$ & 0.3861 & square mile $\left(\mathrm{mi}^{2}\right)$ \\
\hline
\end{tabular}

Horizontal coordinate information is referenced to the North American Datum of 1983 (NAD 83). 


\title{
Gunnison Sage-Grouse Lek Site Suitability Modeling
}

\author{
By Douglas S. Ouren ${ }^{1}$, Drew A. Ignizioํ, Melissa Siders², Theresa Childers ${ }^{3}$, Karen Tucker ${ }^{2}$, and Nathan Seward ${ }^{4}$
}

\begin{abstract}
In order to better understand and protect species with minimal or decreasing populations, it is imperative to determine their actual existing population size. The focal species for this project is the Gunnison sage-grouse (GUSG), which became a proposed endangered species under the Endangered Species Act, thus confirming the need for better population estimates. Lek site counting during mating season has historically been the primary method for estimating population size since the grouse are very difficult to count at other times of the year. The objective of this project was to use historical data and available technology to identify additional potential lekking sites. This was done by determining areas throughout the study area that have the same landscape characteristics as those where known lekking activities occur. More accurate population counts could be the outcome of locating more lek sites.

One of the remaining seven GUSG populations, the Crawford population (estimated at 128 individuals) exists in an area that includes the Gunnison Gorge National Conservation Area and the northern portion of the Black Canyon of the Gunnison National Park (our study area). While the Crawford population is small, it is still considered a self-sustaining population; the persistence and growth of this population directly contribute to genetic diversity conservation of this declining species. To date, only observational and anecdotal information about the Crawford population's range, movements, and seasonal habitat use exist.

From 1978 to the present, GUSG population monitoring has been accomplished through annual lek counts conducted each spring during GUSG mating season. Although this method has provided information on GUSG population trends, it is somewhat limited because counts are based only on known lekking sites and historically minimal efforts have been made to identify additional lek sites. To meet the objective of locating more potential lekking sites, we used a suite of spatial data, geographic information system tools, and maximum entropy species distribution tools. Based on expert knowledge and landscape variables, the modeling process evolved into a hybrid approach for delineating areas that would have a significant probability for supporting GUSG lekking activities. Based on model results, a sampling protocol was developed for model verification. The results of this project provide wildlife managers with a more sophisticated methodology to evaluate GUSG habitat for potential lekking sites.
\end{abstract}

\section{Introduction}

Prior to the early 1980s, it was assumed that there was one species of sage-grouse throughout North America. In 1991, however, researchers noted that the plumage and vocalization characteristics of sage-grouse inhabiting the Gunnison River Basin of Colorado differed from those of sage-grouse

\footnotetext{
${ }^{1}$ U.S. Geological Survey, Fort Collins Science Center, Fort Collins, Colo.

${ }^{2}$ Bureau of Land Management, Uncompahgre Field Office, Montrose, Colo.

${ }^{3}$ National Park Service, Curecanti National Recreation Area, Black Canyon of the Gunnison National Park, Gunnison, Colo.

${ }^{4}$ Colorado Parks and Wildlife, Gunnison, Colo.
} 
occurring elsewhere (Hupp and Braun, 1991). In 1991, Drs. Clait Braun and Jessica Young proposed that the Gunnison sage-grouse (GUSG) was indeed a unique species.

Based on long-term monitoring (since 1978) of sage-grouse lekking activity (leks are display areas where mating takes place), populations of GUSG are declining. As of August 2012, the GUSG was considered a species of special concern by all Federal and state natural resource management agencies throughout its range. One of the remaining seven populations, the Crawford population (estimated at 128 individuals), inhabits the Bureau of Land Management's (BLM) Gunnison Gorge National Conservation area and the North Rim of the Black Canyon of the Gunnison National Park, which we refer to herein as the "Crawford study area" (fig. 1). Although the Crawford population is small, it is considered a "genetically discrete unit and can be considered as a distinct population" (Oyler-McCance and others, 2005); thus, the persistence and growth of this population directly contributes to conserving the overall genetic diversity of this declining species.

Alteration and loss of sage-steppe habitat are suspected of causing declines in GUSG populations. For example, since European settlement in the Gunnison Basin, a lack of fire (due to fire suppression), and mechanical disturbance (hydro axing) have led to encroachment of Rocky Mountain juniper (Juniperus scopulorum) in this sagebrush ecosystem (Crawford and others, 2004). To date, however, there is only observational and anecdotal information about the Crawford population's range, movements, and seasonal habitat use. To effectively target areas for GUSG conservation work, such as habitat-management prescriptions, decisionmakers and planners need empirical evidence of the Crawford population's range and movements.

\section{Problem Statement}

Sage-grouse lekking activity has been monitored in the Crawford study area since 1978, and to date, 10 lek sites have been identified. It is not clear, however, whether the Crawford population uses additional lek sites. Managers need this kind of information to better protect and manage for the population's persistence and growth. Data acquired through the long-term lek monitoring, as well as new research on sage-grouse ecology, have implications for GUSG management. For example, activity at lek sites and associated lek counts are used to determine GUSG population trends. In turn, this information can be used by management agencies to identify areas of critical concern for preserving GUSG populations.

\section{Objectives}

The overall objective of this project was to use the existing long-term records of GUSG lekking activity (specifically, the lek site locations) and existing environmental data (for example, vegetation type, topographic details) that characterize those lek sites for developing a lek site suitability map for the entire Crawford study area. This information will serve as the foundation for future inventory and monitoring, management, and research efforts on National Park Service (NPS), Bureau of Land Management (BLM), State of Colorado, and private (such as those enrolled in Natural Resources Conservation Service programs) lands. More specifically, our objectives were to:

1. use existing data to map the locations of known GUSG lek sites;

2. develop spatially explicit models to identify areas with characteristics similar to those of the known lek sites;

3. combine model results with expert knowledge about GUSG ecology to help identify other locations in the Crawford study area that may be suitable for GUSG lekking activity; and 
4. establish sampling points in areas identified as suitable for lekking activity to use in assessing and validating model outputs and informing future research.

\section{Study Area}

The Crawford study area consists of approximately 880 square kilometers $\left(\mathrm{km}^{2}\right)$ in southwestern Colorado, and includes parts of Delta, Montrose, and Gunnison counties. The region is managed by various Federal and state agencies and private landowners, including the NPS, the BLM, and the U.S. Department of Agriculture Forest Service (FS), as shown in figure 1. 


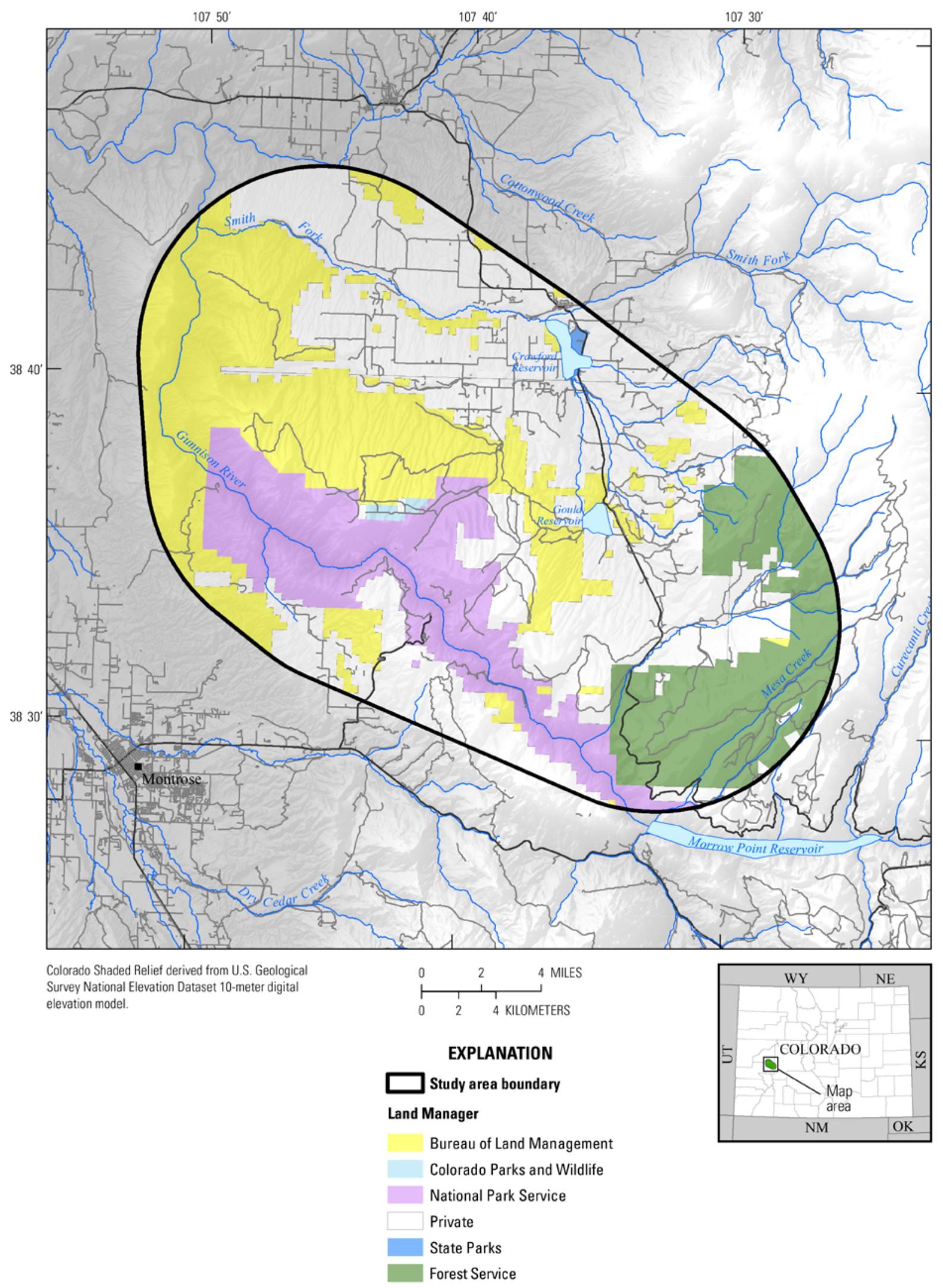

Figure 1. The Crawford study area, including jurisdictional boundaries. 
The study area provides habitat for a wide variety of species, and it supports multiple uses, including livestock grazing and resource extraction. Elevations in the area range from 2,130-2,880 meters $(\mathrm{m})$. Vegetation in the lowest elevations $(2,130 \mathrm{~m}$ to approximately $2,500 \mathrm{~m})$ is dominated by saltbush (Atriplex spp.) and greasewood (Sarcobatus vermiculatus). From elevations of 2,420-2,880 m, short grasses, yucca (Yucca baccata), Wyoming big sagebrush (Artemisia tridentata ssp. wyomingensis), and Rocky Mountain juniper (Juniperus scopulorum) comprise the majority of the vegetation.

\section{Methods}

\section{Modeling Approach}

The modeling approach for this project was to use the maximum entropy species distribution modeling package, or Maxent (Phillips and others, 2006), to help identify and classify (for ranking) areas possessing ecological characteristics similar to those of the known GUSG lek sites. Maxent is a statistical model that estimates the distribution of a phenomenon based on a certain set of conditions (Phillips and others, 2006). Using existing records of a species' presence (locations) within a given landscape, the software can be used to estimate the probability of that species' occurrence elsewhere within the same landscape. The decision to use the Maxent software for the analysis was based on its wide use in species-distribution modeling (Austin, 2007; Elith and Graham, 2009; Hernandez and others, 2006) and the fact that it is one of the few modeling packages designed to use presence-only data, a feature of the data used in this project (Phillips and others, 2006).

A user must provide at least two inputs to the Maxent model: (1) point locations of the species' known occurrences (referred to as "presence points"), and (2) a set of environmental predictor variables (hereafter variables) that collectively help to explain the species' distribution. The set of variables should be informed by the species' ecological needs and typically includes elevation, vegetation type, and other crucial landscape characteristics (Phillips and others, 2006). Users have the option of configuring parameters that determine how the Maxent model is trained and run, including the extent of the training area, the extent of the variability it captures for each variable, and the number of model runs to be conducted. Using an algorithmic approach, Maxent combines information about the characteristics of each variable at the presence points to score novel areas in the landscape. Areas exhibiting characteristics more similar to those at the presence points are assigned higher scores. In the context of this study, higher scores represent a higher modeled likelihood of suitability for lekking activity.

We ran several different preliminary models to evaluate various strategies for establishing presence points and selecting the appropriate variables, with varying degrees of success. After reviewing these outputs, we identified an approach, described below, that maximized our confidence in the modeled results given the limitations of the existing lek data. The final lek suitability analysis of the Crawford study area entailed a hybrid approach that refines, a posteriori, the output of a simplified Maxent model by applying a binary filter to ensure that all areas modeled met certain minimum criteria. More specifically, the binary filter, which was based on expert knowledge about the general characteristics of known lek sites, was used to exclude areas that did not meet the minimum criteria for lekking activity, thus restricting the overall area for which model scores were generated. Then we ranked the remaining areas according to their suitability (modeled likelihood scores) for lekking activity. 


\section{Presence Points}

A digital dataset representing the boundaries (polygons) of 10 known lek sites within the Crawford study area was used for generating the presence points used in the modeling effort. The lek sites were reviewed visually by using ArcMap (ESRI, 2010) desktop geographic information system (GIS) software in conjunction with a basemap (aerial imagery at 1-m resolution) from the ESRI online data library (http://www.esri.com/data/free-data/index.html) and a raster layer (30-m resolution) depicting slope. Although all of the polygons in the lek dataset generally encompassed areas that appeared to have lek site potential, many of the polygons also included wide swaths of land that were deemed unlikely to be suitable for lekking activity (for example, areas characterized by heavy tree cover). Presence points were generated by manually placing them within the polygons outlining known leks. These points were recorded as latilong values. A total of 11 points were generated, 1 in each of 9 lek polygons and 2 in a particularly large and irregularly shaped lek polygon. Rather than randomly generating points within the polygons, points were specifically placed within the lek polygons in areas with sparse vegetation and low slope values. We did this so that the presence points would represent locations that possess the characteristics most representative of known sage-grouse lek sites. These points were used as the presence locations in the Maxent model.

\section{Environmental Predictor Variables}

The final set of environmental predictor variables was selected on the basis of their availability as spatial data and a desire to use a concise but relevant group of variables that collectively could help to identify areas that are relatively flat and sparsely vegetated - characteristics believed to be shared by most leks. Three of the variables, wetness, greenness, and brightness, were GIS layers derived from tasseled cap transformation (Crist and Cicone, 1984) of Landsat Thematic Mapper (TM) imagery (path 35, row 33, capture date May 11, 2007). Wetness represents soil and canopy moisture, greenness is a general indicator of vegetation, and brightness is a measure of bare soil. From the Landsat TM imagery we also derived a raster layer of the normalized difference vegetation index (NDVI) to see whether it could help us identify differences in vegetation. We included distance to water to determine whether water features on the landscape affect suitability for lekking activity. Elevation and slope were included based on the generally accepted belief that areas occupied by sage-grouse are restricted to a certain range of elevations and that lekking takes place in primarily flat areas. The final Maxent model was run using the variables shown in table 1. 
Table 1. Environmental predictor variables used in final Maxent model of lek suitability for Gunnison sage-grouse.

\begin{tabular}{|c|c|c|c|}
\hline $\begin{array}{l}\text { Environmental } \\
\text { predictor variable }\end{array}$ & Source & Raster resolution (m) & Date of source material \\
\hline $\begin{array}{l}\text { Digital Elevation } \\
\text { Model (DEM) }\end{array}$ & National Elevation Dataset & 1 arc second $(\sim 30 \mathrm{~m})$ & 2009 \\
\hline Slope & National Elevation Dataset & 1 arc second $(\sim 30 \mathrm{~m})$ & 2009 \\
\hline Distance to water & $\begin{array}{l}\text { BLM, Uncompahgre Field } \\
\text { Office }\end{array}$ & 30 & 2009 \\
\hline Vegetation type & $\begin{array}{l}\text { Colorado Vegetation } \\
\text { Classification Map from the } \\
\text { Colorado Division of Wildlife }\end{array}$ & 25 & $\begin{array}{l}\text { Source imagery } \\
\text { originally captured } \\
\text { 1993-1997 }\end{array}$ \\
\hline Wetness & $\begin{array}{l}\text { Derived from tasseled cap } \\
\text { transformation of Landsat TM } \\
\text { imagery (Path: 35, Row: } 33 \text { ) }\end{array}$ & 30 & May 11, 2007 \\
\hline Greenness & $\begin{array}{l}\text { Derived from tasseled cap } \\
\text { transformation of Landsat TM } \\
\text { imagery (Path: 35, Row: 33) }\end{array}$ & 30 & May 11, 2007 \\
\hline Brightness & $\begin{array}{l}\text { Derived from tasseled cap } \\
\text { transformation of Landsat TM } \\
\text { imagery (Path: 35, Row: } 33 \text { ) }\end{array}$ & 30 & May 11, 2007 \\
\hline
\end{tabular}

Preparation of the spatial variables and the Maxent modeling analysis was conducted with the VisTrails software package (Callahan and others, 2006), in which we used a custom module developed at the U.S. Geological Survey (USGS) Fort Collins Science Center. This module facilitated the processing of all the environmental predictor raster layers prior to their use in Maxent. All layers were re-projected into, and analysis was conducted in, the Universal Transverse Mercator (UTM) zone 13 North projection, based on the North American Datum of 1983. The resolution of all inputs was $30 \mathrm{~m}$, either because their native resolution was $30 \mathrm{~m}$ or the data were re-sampled to yield a $30-\mathrm{m}$ resolution.

The custom VisTrails module also allowed us to review the degree of correlation between each variable and drop from the model any layers that were highly correlated. We conducted Pearson, Spearman, and Kendall correlation tests and considered the largest coefficient values for assessing the degree of correlation between variables. We used a cutoff value of 0.7 to exclude individual layers from highly correlated pairs of variables. The raster image of the NDVI was dropped from the Maxent model because it correlated strongly with the greenness index $(\mathrm{r}=0.77)$.

\section{Training Site and Variables Used in the Maxent Model}

An essential step to implementing the Maxent modeling package is training the model. Within the Maxent software, a user has the option to customize the area or geographic extent in which the software will train the model, as well as the number of "background points" that Maxent casts throughout the training area to capture the range of variability for each variable. Comparing the values of the variables at all of the background points to their values at the presence points helps the model determine which predictor variables may be influencing the distribution of the lek sites. 
All 10 of the known lek sites are clustered together in a relatively small area located near the center of the Crawford study area (fig. 1), thus the presence points are also spatially clustered together. To overcome potential spatial bias created by this clustering, the Maxent model was trained within a rectangular area of 6.6 x 1.5 kilometers (approximately $10.5 \mathrm{~km}^{2}$ ) immediately surrounding the existing lek polygons and then applied to the rest of the study area.

A total of 1,000 background points were randomly distributed within the training area. Eleven replicate model runs were performed in Maxent with the "cross-validate" option. In cross-validating each model run, each presence point was dropped one at a time to overcome any sensitivity the model might have to extraneous or outlier values at a single presence point. The final Maxent model output values (scores) represent the average of all 11 model runs.

\section{Final Model Development}

After training and running the model, the results were projected onto the entire polygon of the Crawford study area. Additional refinement was subsequently performed outside of Maxent to account for trends witnessed in the training area and to include general knowledge about the known lek sites within the study area. We addressed these considerations by masking the Maxent results based on the criteria listed below and restricted model predictions to a region defined by some general expectations about sage-grouse lekking activity.

The mask we used to refine the Maxent results was based on the conditions present at known lek sites. The mask was developed by using a binary filter comprising three variables used to exclude completely unsuitable areas from the modeled results. The three variables used to refine the areas potentially suitable for lekking activity and the range of values considered acceptable for each variable are shown in table 2.

Table 2. Environmental predictor variables and the range of values considered acceptable for each variable in the final model.

\begin{tabular}{ll}
\hline Environmental predictor variable & \multicolumn{1}{c}{ Inclusive values } \\
\hline Vegetation type & $\begin{array}{l}\text { Sagebrush/grass mix, sagebrush community, or grass forb } \\
\text { rangeland }\end{array}$ \\
Elevation & $2,310-2,420 \mathrm{~m}$ \\
Slope & Less than 8 degrees \\
\hline
\end{tabular}

For vegetation type, we masked out areas not classified as grass forb rangeland, sagebrush community, or sagebrush/grass mix, (the known Crawford lek sites and the training area were vegetated almost entirely with these types). For elevation, we retained only areas between 2,310 and 2,420 m (mean elevation in the model training area was $2,364.5 \mathrm{~m}$ with a standard deviation of 27.24), and we derived this range of values by adding two standard deviations above and below the mean elevation. For slope, we masked out areas where the slope was greater than 8 degrees (mean slope of the known lek sites was 6.4 degrees, the standard deviation was 1.5, and the upper slope threshold was derived by adding one standard deviation to the mean). Figures 2-4 depict the areas that met the vegetation type, elevation, and slope criteria, respectively). Areas that met all three criteria were determined to be potentially suitable for lekking activity (fig. 5). The Maxent results were clipped to the area within the Crawford study area that met all three criteria; areas that did not meet the criteria were not scored. 


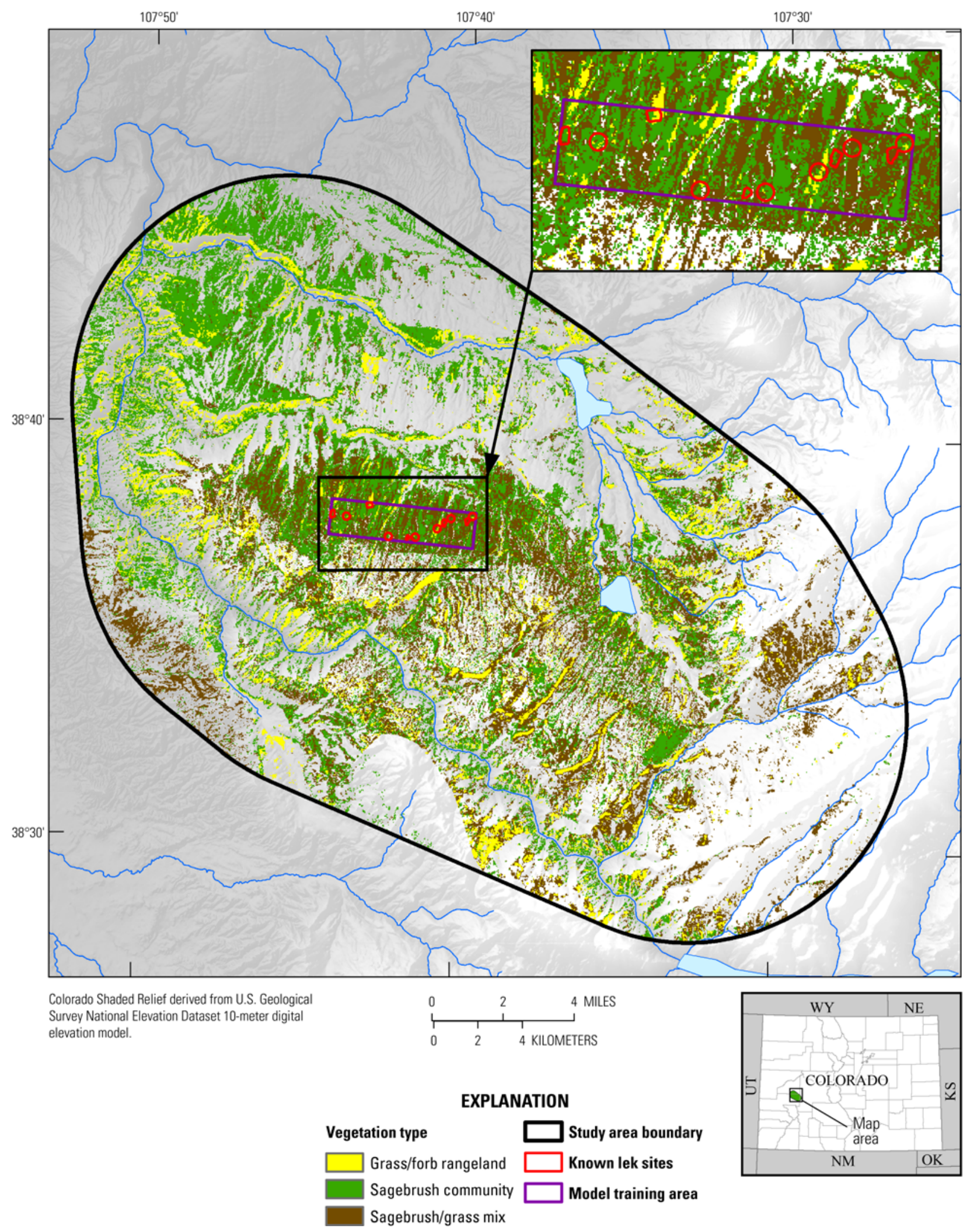

Figure 2. Vegetation types in the Crawford study area considered potentially suitable for sage-grouse lekking activity. 


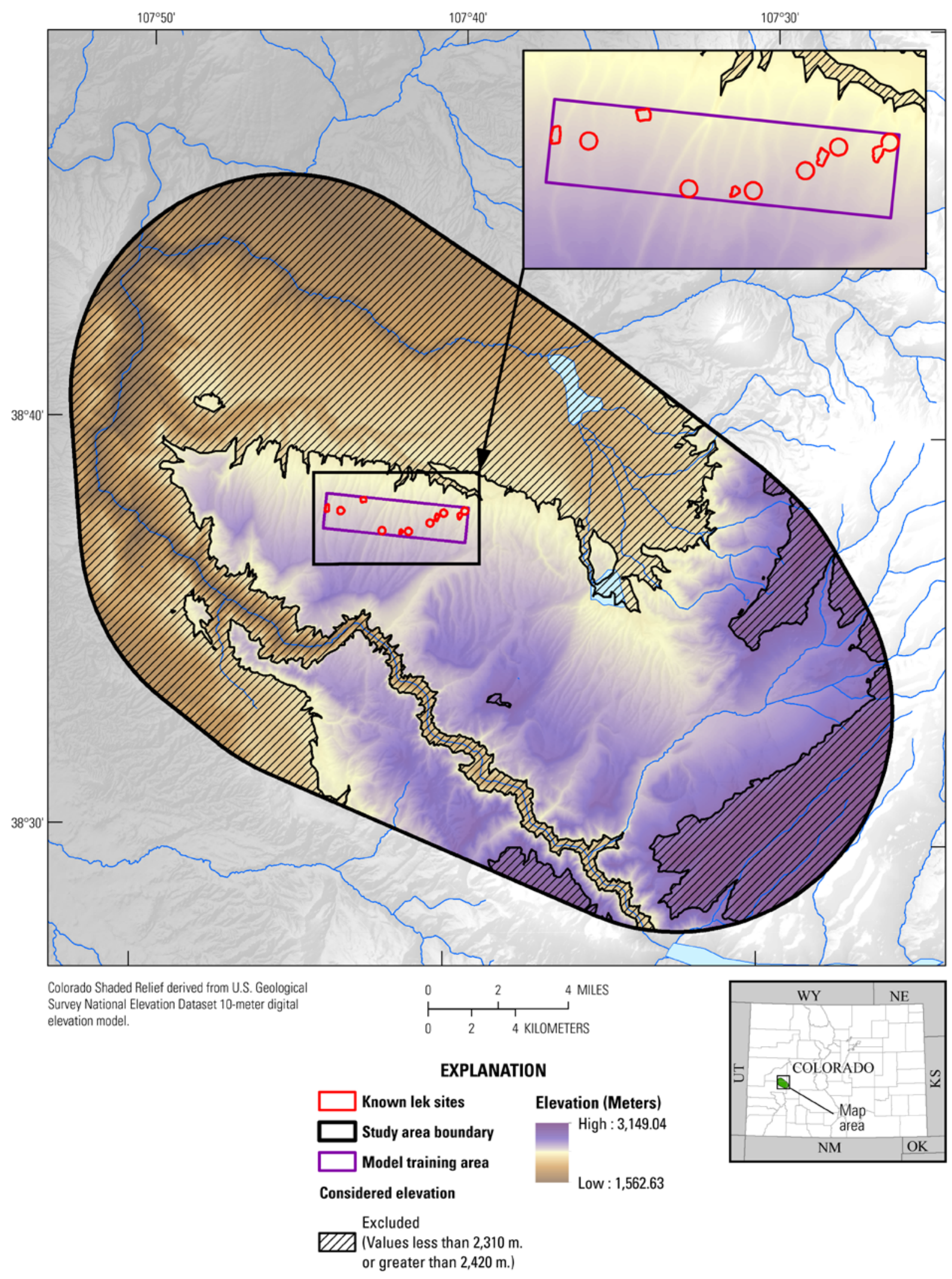

Figure 3. The range of elevation values in the Crawford study area and which were considered potentially suitable $(2,310-2,420 \mathrm{~m})$ for lekking activity (hatching indicates areas excluded from the model). 


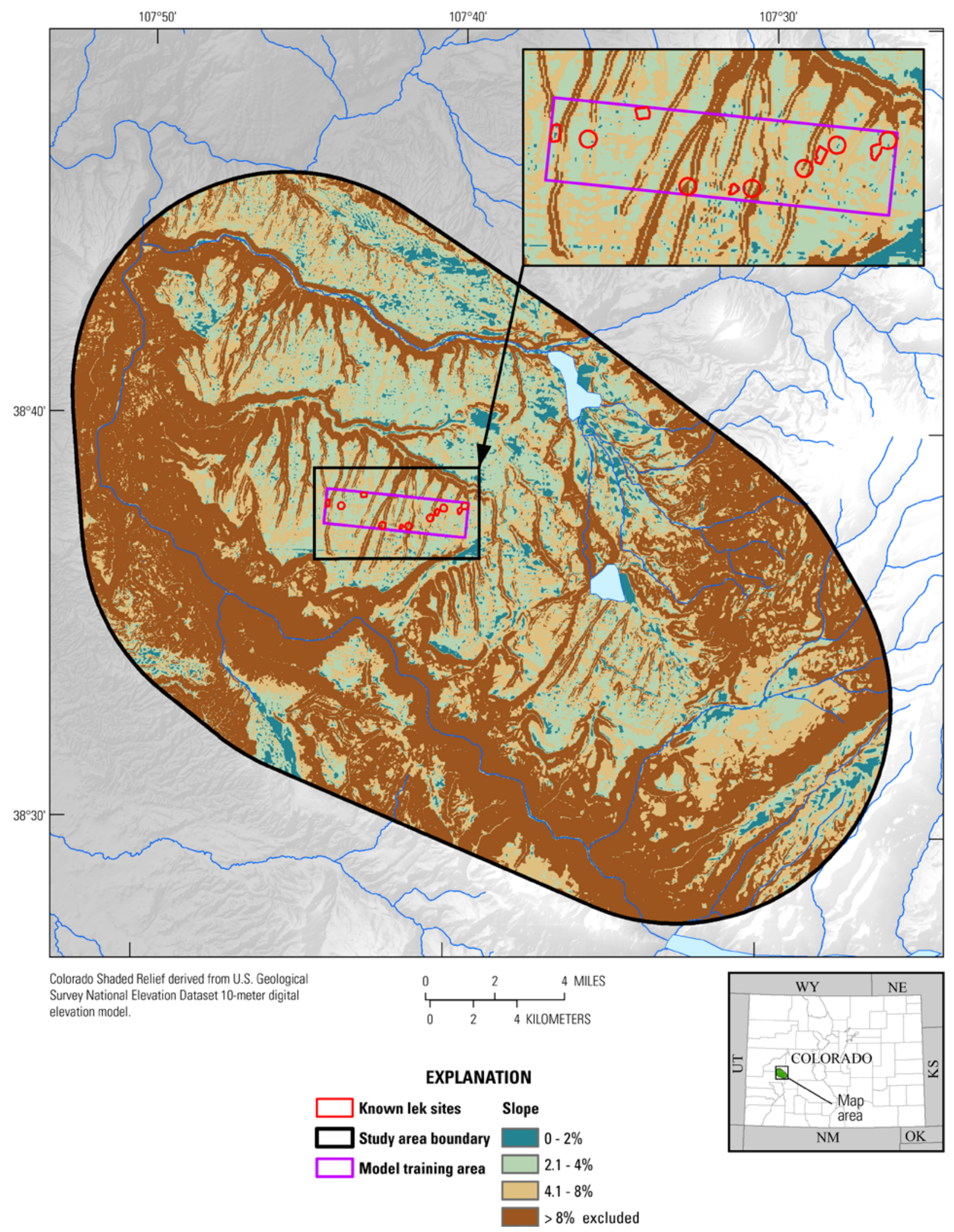

Figure 4. The range of slope values in the Crawford study area (shown in the inset) and which regions were considered potentially suitable (8 degrees or less) for lekking activity (shown as brown in the large polygon). 


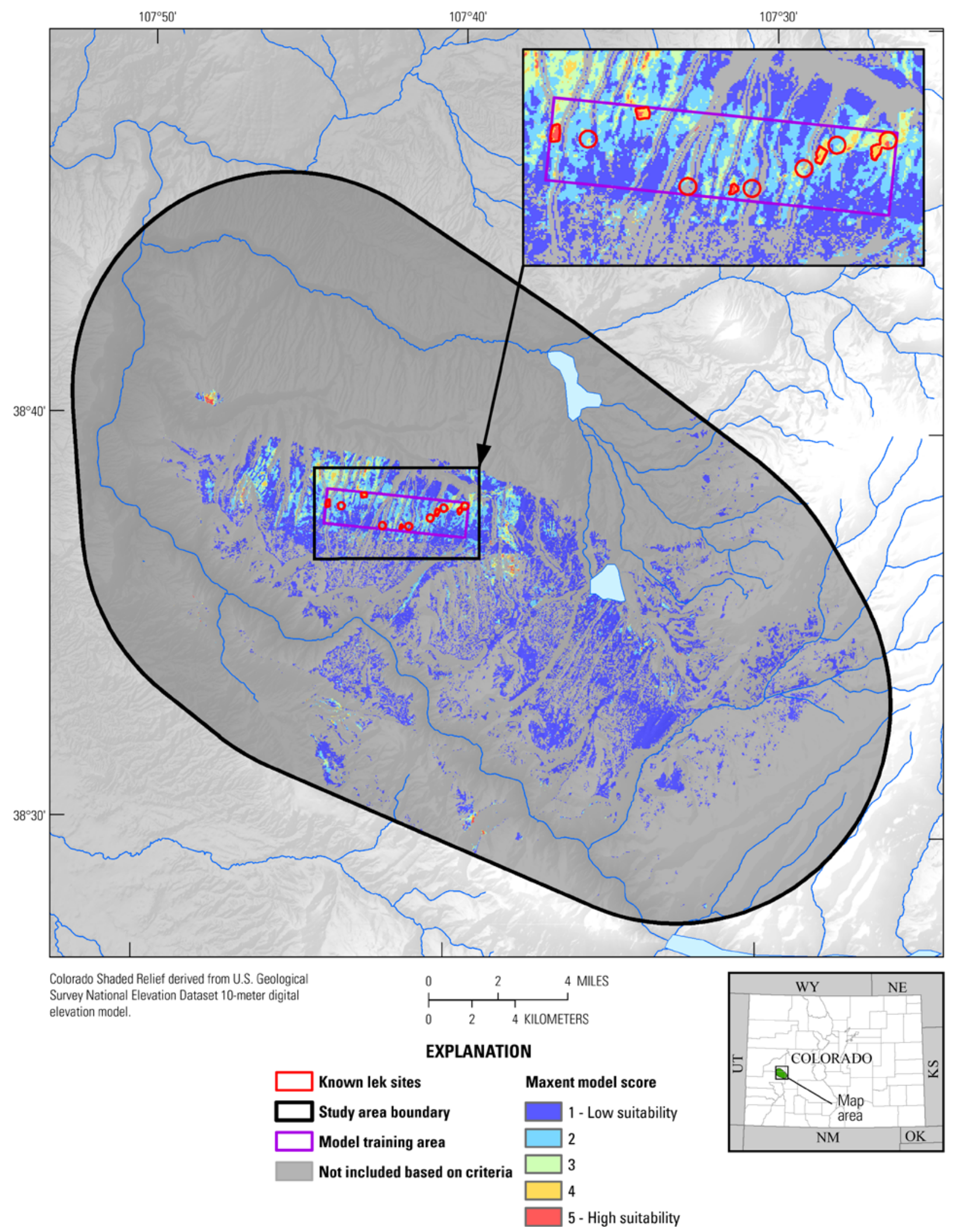

Figure 5. Areas considered potentially suitable for lekking activity (white areas) in the Crawford study area, based on slope, elevation, and vegetation type present at known leks. 


\section{Results}

Output values from the Maxent model range from 0 to 1 , with higher values representing a higher likelihood for occurrence of the phenomenon modeled - in this case, conditions suitable for lekking activity. For analysis purposes, the results of the Maxent model were divided into five classes for ranking them according to their level of suitability. The classes were obtained by applying five equal intervals to the final range of output values in the Maxent (table 3). These five classes, and their associated ranks, are shown in table 3.

Table 3. Maxent output values, by class, associated rank assignments, and rank interpretations.

\begin{tabular}{ccl}
\hline Maxent output value classes & Ranks & \multicolumn{1}{c}{ Description } \\
\hline $0.00-0.19$ & 1 & Low suitability for lekking activity \\
$0.20-0.39$ & 2 & Low-to-medium suitability for lekking activity \\
$0.40-0.58$ & 3 & Medium suitability for lekking activity \\
$0.59-0.77$ & 4 & Medium-to-high suitability for lekking activity \\
$0.78-0.96$ & 5 & High suitability for lekking activity \\
\hline
\end{tabular}

The results of this project will be used by management agencies, including the BLM, NPS, and the FS, to assist in developing monitoring strategies for locating currently unknown lekking areas. We ranked the Maxent results to help land managers identify priority regions and areas of potential interest within their domains. Tables 4 and 5 provide a breakdown of the model results by suitability category and jurisdiction before and after the application of the binary filter.

Initial Maxent output before applying the filter represented an area of $862 \mathrm{~km}^{2}$ (slightly less than the whole Crawford study area; there were a few missing regions of Landsat TM data, so Maxent did not generate results for these areas). After applying the binary filter, the area was reduced to $105 \mathrm{~km}^{2}$ (fig. 5). Although the entire $105 \mathrm{~km}^{2}$ area represents potentially suitable lekking habitat, the predicted suitability for GUSG lekking activity is greater in areas with higher ranks (classes 4-5) and less for areas with lower ranks (classes $<4$ ). 
Table 4. Suitability of the Crawford study area (percent) for lekking activity as modeled by Maxent, by jurisdiction, before application of the binary filter. To help resource managers separate the more suitable sites from those less suitable, the Maxent output scores were assigned to five equal classes, or ranks, with a rank of 1 representing areas least suitable and a rank of 5 representing the areas most suitable for lekking activity.

\begin{tabular}{|c|c|c|c|c|c|c|c|c|c|c|}
\hline & Maxent & Class 1 & Maxent & Class 2 & Maxent & Class 3 & Maxent & Class 4 & Maxent & Class 5 \\
\hline Jurisdiction & Percent & $\begin{array}{l}\text { Area } \\
\left(\mathrm{km}^{2}\right)\end{array}$ & Percent & $\begin{array}{l}\text { Area } \\
\left(\mathrm{km}^{2}\right)\end{array}$ & Percent & $\begin{array}{l}\text { Area } \\
\left(\mathrm{km}^{2}\right)\end{array}$ & Percent & $\begin{array}{l}\text { Area } \\
\left(\mathrm{km}^{2}\right)\end{array}$ & Percent & $\begin{array}{l}\text { Area } \\
\left(\mathrm{km}^{2}\right)\end{array}$ \\
\hline Private & 41.05 & 274.57 & 46.42 & 30.00 & 51.82 & 18.70 & 56.57 & 16.38 & 49.33 & 31.49 \\
\hline $\begin{array}{l}\text { Bureau of Land } \\
\text { Management }\end{array}$ & 24.96 & 166.99 & 44.64 & 28.85 & 41.07 & 14.82 & 36.74 & 10.63 & 30.91 & 19.73 \\
\hline Forest Service & 14.07 & 94.14 & 4.34 & 2.80 & 4.68 & 1.69 & 4.65 & 1.35 & 18.71 & 11.95 \\
\hline $\begin{array}{l}\text { Colorado State } \\
\text { Parks }\end{array}$ & 0.42 & 2.81 & 0.19 & 0.12 & 0.19 & 0.07 & 0.10 & 0.03 & 0.05 & 0.03 \\
\hline $\begin{array}{l}\text { National Park } \\
\text { Service }\end{array}$ & 19.14 & 128.05 & 4.40 & 2.84 & 2.24 & 0.81 & 1.94 & 0.56 & 0.99 & 0.63 \\
\hline $\begin{array}{l}\text { Colorado Parks } \\
\text { and Wildlife }\end{array}$ & 0.35 & 2.37 & 0.01 & 0.00 & 0.00 & 0.00 & 0.00 & 0.00 & 0.00 & 0.00 \\
\hline Total & 100.00 & 668.92 & 100.00 & 64.62 & 100.00 & 36.08 & 100.00 & 28.95 & 100.00 & 63.84 \\
\hline $\begin{array}{l}\text { Percent of total } \\
\text { modeled area }\end{array}$ & 77.56 & & 7.49 & & 4.18 & & 3.36 & & 7.40 & \\
\hline
\end{tabular}


Table 5. Suitability of the Crawford study area (percent) for lekking activity, as modeled by Maxent, by jurisdiction, after applying the binary filter. To help resource managers separate the more suitable sites from those less suitable, the Maxent output scores were assigned to five classes, or ranks, with a rank of 1 representing areas least suitable and a rank of 5 representing the areas most suitable for lekking activity.

\begin{tabular}{|c|c|c|c|c|c|c|c|c|c|c|}
\hline & Maxent & Class 1 & Maxent & Class 2 & Maxent & Class 3 & Maxent & Class 4 & Maxent & Class 5 \\
\hline Land Manager & Percent & $\begin{array}{l}\text { Area } \\
\left(\mathrm{km}^{2}\right)\end{array}$ & Percent & $\begin{array}{l}\text { Area } \\
\left(\mathrm{km}^{2}\right)\end{array}$ & Percent & $\begin{array}{c}\text { Area } \\
\left(\mathbf{k m}^{2}\right)\end{array}$ & Percent & $\begin{array}{l}\text { Area } \\
\left(\mathrm{km}^{2}\right)\end{array}$ & Percent & $\begin{array}{l}\text { Area } \\
\left(\mathrm{km}^{2}\right)\end{array}$ \\
\hline Private & 45.62 & 37.69 & 13.10 & 2.02 & 10.99 & 0.56 & 16.92 & 0.21 & 35.56 & 0.13 \\
\hline $\begin{array}{l}\text { Bureau of Land } \\
\text { Management }\end{array}$ & 35.74 & 29.52 & 80.76 & 12.46 & 86.82 & 4.45 & 81.73 & 1.01 & 62.07 & 0.23 \\
\hline Forest Service & 3.30 & 2.73 & 0.06 & 0.01 & 0.00 & 0.00 & 0.00 & 0.00 & 0.00 & 0.00 \\
\hline $\begin{array}{l}\text { National Park } \\
\text { Service } \\
\text { Colorado } \\
\text { Division } \\
\text { of Wildlife }\end{array}$ & 14.46 & 11.95 & 0.02 & 0.00 & 0.00 & 0.00 & 0.00 & 0.02 & 0.00 & 0.00 \\
\hline Total & 100.00 & 82.61 & 100.00 & 15.42 & 100.00 & 5.13 & 100.00 & 1.23 & 100.00 & 0.37 \\
\hline $\begin{array}{l}\text { Percent of total } \\
\text { modeled area }\end{array}$ & 78.86 & & 14.72 & & 4.90 & & 1.17 & & 0.35 & \\
\hline
\end{tabular}

\section{Model-Guided Sampling Efforts}

In addition to being relevant for land management concerns, the development of this classified suitability surface may be used to guide the design of sampling methods for finding additional active GUSG leks within the Crawford study area. After reviewing the model output, 200 sample points separated by at least $200 \mathrm{~m}$ were scattered throughout the entire area in which output scores were assigned. Because such a small proportion of the total scored area was ranked as highly suitable (4 or 5), an additional 50 sampling points were scattered in the two areas ranked as 4 or 5 . Due to the small sizes of these areas, a minimum point-separation distance was not enforced when generating these additional points. These points have since been provided to field crews as way to help guide sampling efforts in the field and are useful method for concentrating observation efforts in a relatively large study area. Furthermore, the results of the field crews' sampling efforts will help to validate the Maxent model results and inform any future modeling approaches.

\section{Discussion}

The Maxent model provided two metrics for assessing which variables were most important in determining model results: the percent contribution and the permutation importance. Generally speaking, the percent contribution is a measure of how much a single variable contributed to the results for a single model run, while permutation importance provides a measure of how consistently a variable contributed to the results across multiple model runs (table 6). 
Table 6. Relative contribution of environmental predictor variables used in the Maxent model for lek site suitability.

\begin{tabular}{lcc}
\hline \multicolumn{1}{c}{ Environmental predictor variable } & Percent contribution & Permutation importance \\
\hline Brightness & 90.1 & 88.6 \\
Slope & 8.4 & 9.2 \\
Greenness & 0.9 & 1.5 \\
Elevation & 0.3 & 0.2 \\
Distance to water & 0.2 & 0.5 \\
Vegetation type & 0.1 & 0 \\
\hline
\end{tabular}

After investigating the percent contribution of each variable to the model output, it appears that while vegetation type is widely recognized as a factor in determining lek site distribution, Maxent did not identify the vegetation data layer used in this analysis as a significant indicator for lek presence. This may indicate that the vegetation data layer (categorical data at a $30-\mathrm{m}$ resolution) does a poor job of representing the actual land cover characteristics within the landscape, and/or it may indicate that at the point level, vegetation functions poorly as a predictor for lek sites. Future research might evaluate the contribution of landscape composition at various scales (that is, analysis of vegetation and terrain characteristics within different distances from an observed lek). Because sage-grouse likely select lek sites based on the overall characteristics of an area rather than on the single vegetation type assigned to a 30-m cell, this approach would yield results from a more informed ecological perspective. It should be noted that although Maxent did not identify vegetation type as a predictor for lek sites, this does not mean that vegetation characteristics at the landscape level were not relevant in the Maxent model output. The brightness and greenness variables derived from the Landsat TM imagery capture valuable information about vegetation composition, and both of these datasets were used in Maxent to generate predicted lek suitability scores.

Application of the binary filter was an effective means of removing regions that appeared to have been assigned illogically high suitability scores by the Maxent model (this is illustrated by comparing tables 4 and 5). The land cover type of some areas to which Maxent assigned high suitability scores is unlikely to be used for lekking activity. These seemingly spurious Maxent results may be explained by the fact that the categorical vegetation predictor was effectively excluded from consideration in model. The contribution of brightness to the model also helps to explain these results. Brightness, which was the single most influential predictor layer used in the Maxent model, is generally effective at identifying the sparsely vegetated areas associated with lek activity, but it also effectively identifies other land cover types (such as agricultural areas or snow-covered peaks) unlikely to be used for lekking activity. Also, probably due to the relatively minimal elevational variation in the training area, Maxent did not identify elevation as having a strong role in distinguishing between presence points and background points. Consequently, the Maxent model identified some improbable regions at very high elevations as being highly suitable for lekking activity.

Combining the Maxent results with existing knowledge about the known lek sites allowed us to refine the results and restrict model scores to regions that met certain conditions needed for GUSG lekking activity. This hybrid technique provides the benefits of a simple binary model (regions are classified as usable or not based on an established set of criteria) and a traditional Maxent-based approach (a continuously scored output is produced, allowing distinction between the different areas identified as being potentially suitable).

In any modeling application, projecting results into a region different from where the model was trained or developed can present a challenge. Such a scenario however, can be difficult to avoid when 
the recorded observations used to develop a model are limited in number or spatial distribution throughout a landscape. With the dataset representing known lek locations used in this project, these were both known limitations. The unexpected Maxent predictions in certain regions are most likely attributable to these issues. The various measures included to address these shortcomings include the use of cross validation, limiting the training area for the model to a region defined by the spatial bias in the lek locations, eliminating highly correlated variables, and applying the binary filter outlined above to the final model results. It is also worth noting that the range or threshold of filter values selected was based only on the known lek sites in the Crawford region. While it is assumed that sage-grouse in other regions will select for similar areas, they may exhibit slightly different behaviors or select for landscape characteristics we have not captured here.

While the final output product of any model is only as good as the quality of the initial data, we used the best data currently available to conduct a valuable investigation of lek site suitability in the Crawford area. We are confident that our results provide the information needed to develop sampling transects for identifying additional GUSG lek sites. The next step in the process would be to use the results of new monitoring efforts to validate the model output and determine whether we can find any other areas used by GUSG for lekking activity within the Crawford Study area.

\section{Acknowledgments}

This project was supported by funding from the National Audubon Society. We are most grateful to Doug Homan for providing the history of GUSG monitoring and other information. We also would like to thank the Bureau of Land Management, National Park Service, and the Colorado Division of Parks and Wildlife for their assistance on this project.

\section{References}

Austin, Mike, 2007, Species Distribution Models and Ecological Theory-A critical assessment and some possible new approaches: Ecological Modelling, v. 200, nos. 1-2, p. 1-19.

Callahan, S.P., Freire, J., Santos, E., Scheidegger, C.E., Silva, C.T., and Vo, H.T., 2006, VisTrails: Visualization meets data management, in Association for Computing Machinery, Special Interest Group on Management of Data (ACM SIGMOD) 2006, June 27-29, 2006, Chicago, Illinois, Proceedings: Association for Computing Machinery, Special Interest Group on Management of Data (ACM SIGMOD), p. 745-747.

Crawford, J.A, Olson, R.A., West, N.E., Mosley, J.C., Schroeder, M.A., Whitson, T.D., Miller, R.F., Gregg, M.A., and Boyd, C.S., 2004, Synthesis paper: Ecology and management of sage-grouse and sage-grouse habitat: Journal of Range Management, v. 57, no. 1, p. 2-19.

Crist, E.P., and Cicone, R.C., 1984, A physically-based transformation of Thematic Mapper data-The TM tasseled cap: IEEE Transactions on Geoscience and Remote Sensing, v. GE-22, no. 3, p. 256263.

Elith, J., and Graham, C.H., 2009, Do they? How do they? WHY do they differ? On finding reasons for differing performances of species distribution models: Ecography, v. 32, no. 1, p. 66-77.

ESRI, 2010, ArcGIS Desktop: Release 10: Redlands, Calif., ESRI.

Hernandez, P.A., Graham, C.H., Master, L.L., and Albert, D.L., 2006, The effect of sample size and species characteristics on performance of different species distribution modeling methods: Ecography, v. 29, no. 5, p. 773-785.

Hupp, J.W. and Braun, C.E., 1991, Geographic variation among sage grouse in Colorado: Wilson Ornithological Society, Wilson Bulletin, v. 102, no. 2, p. 255-261. 
Oyler-McCance, S.J., St. John, J., Taylor, S.E., Apa, A.D., Quinn, T.W., 2005, Population genetics of Gunnison sage-grouse-Implications for management: Journal of Wildlife Management, v. 69, no. 2, p. 630-637.

Phillips, S.J., Anderson, R.P., and Schapire, R.E., 2006, Maximum entropy modeling of species geographic distributions: Ecological Modelling, v. 190, p. 231-259.

Young, J.R., Braun, C.E., Oyler-McCance, S.J., Hupp, J.W., and Quinn, T.W., 2000, A new species of sage-grouse (Phasianidae: Centrocercus) from southwestern Colorado: Wilson Bulletin, v. 112, no. 4, p. $445-453$. 


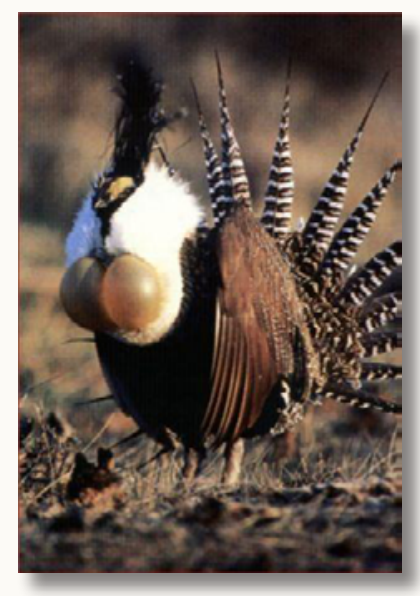

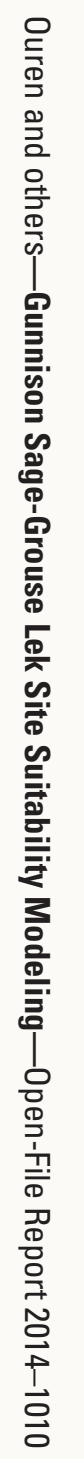

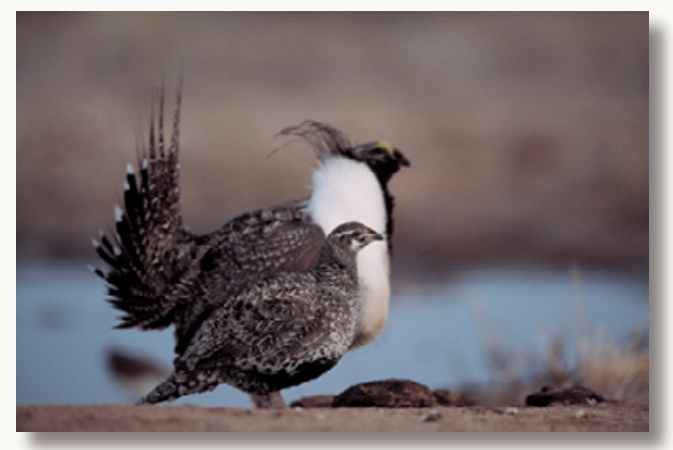

